Original Article, Oncology

\title{
The Effects of TSH level on the Results of F-18 FDG PET/CT in Recurrent Differentiated Thyroid Carcinoma Patients with Elevated Serum Thyroglobulin Level and Negative I-131 WBS.
}

\author{
Kotb, $\mathbf{M}^{*}$. Wafaie, $A^{* *}$. Edward. $\mathbf{R}^{* *}$. Hussein, $\mathbf{M}^{* *} \cdot$ Mostafa, $A^{* * *}$. \\ $\operatorname{Morsy~} \mathbf{A}^{* * *}$ \\ *Nuclear Medicine department, National Cancer Institute. ${ }^{* *}$ Radiology department, \\ Faculty of Medicine. ${ }^{* * *}$ Surgical Oncology department, National Cancer Institute, Cairo \\ University, Egypt.
}

\section{ABSTRACT}

Purpose : To assess the effects of TSH level on F-18 FDG PET-CT results \& its impact on serum thyroglobulin (TG) cut off point and management in recurrent DTC patients with elevated TG level \& negative I-131 WBS. Material and Methods: This prospective work involved 38 histopathologically proved DTC patients underwent total thyroid ablation with elevated serum TG and negative I-131 WBS during follow up. F-18 FDG was done in all patients using standard technique. Results: Patients divided into two groups: (I) Stimulated TSH group (i.e. TSH level > $30 \mathrm{IU} / \mathrm{L}, 60$ \pm 20 IU/L): 20 patients. (II) Suppressed TSH group (i.e. TSH level $<0.1$ IU/L, $0.007 \pm 0.003 \mathrm{IU} / \mathrm{L}): 18$ patients. Significantly higher overall accuracy, sensitivity \& NPV were found in stimulated group $(98.5 \%, 88.6 \%, 62 \%$ respectively) compared to the suppressed group $(66 \%, 62 \% \& 31.5 \%$ respectively) that was more obvious in nodal rather than pulmonary deposits $(\mathrm{P}<0.05)$. However no significant difference was demonstrated in specificity \& PPV between both groups. Significantly lower TG cut off point was demonstrated in stimulated group $(15 \mathrm{ng} / \mathrm{ml})$ compared to suppressed group $(21 \mathrm{ng} / \mathrm{ml}) \quad(\mathrm{P}<0.05)$. Moreover significantly higher impact of F-18 FDG PET-CT in TSH stimulated (40\%) was demonstrated compared to TSH suppressed (11.2\%) group on patient management.

Conclusion: High TSH seems to enhance F-18 FDG PET/CT efficiency on nodal rather than pulmonary metastases in recurrent DTC patients with elevated serum TG level and negative I-131 WBS. Moreover it reduces TG cut off point for F-18 FDG PET-CT \& escalates its impact on patient management.

Key words: FDG PET/CT, TSH, De-DTC. 


\section{INTRODUCTION}

Recurrent differentiated thyroid carcinoma (DTC) with elevated serum thyroglobulin (TG) level and negative I131 WBS represents a diagnostic and therapeutic dilemma in clinical practice. This subset of tumor recurrence called dedifferentiated thyroid carcinoma (DeDTC) in which cellular de-differentiation and tumour progression may occurs ${ }^{(1,2)}$. De-differentiation is genetically based complex process produces multiple molecular changes that progressively transform differentiated tumor into dedifferentiated one with more aggressive behavior and characteristics. These include more aggressive growth, enhanced invasive activity, angio-genesis and increased metastatic spread as well as inability to concentrate radio-iodine (RAI). The latter cause high false negative radio-iodine WBS and making the disease resistant to RA I-131 therapy. In such patients with low diagnostic and therapeutic yield for RAI, precise localization of tumor site is essential to define the therapeutic strategy particularly when surgery is purposed as a curative intent ${ }^{(3,4,5,6,7,8,9,10)}$. Therefore strong need for an alternative effective imaging tool that can predict and detect dedifferentiated lesions is clinically desired. Unsatisfactory results has been reported in the literature regarding the use of conventional morphologic imaging procedures to localize tumour deposits in recurrent De-DTC patients with elevated serum TG levels \& in the absence of thyroglobulin auto-antibodies. In contrast various molecular \& clinical studies demonstrate the effectiveness of F-18 FDG PET/CT in localization of recurrent de-differentiated thyroid carcinoma lesions in those patients. The biological basis of that include up regulation of glucose consumption via over-expressed trans-membrane receptor GlUT-1 by these lesions. On the other hand, the impact of high TSH level on the effectiveness of F-18-FDG PET/CT imaging in recurrent de-differentiated thyroid cancer is not completely certain and lack of agreement is reflected in

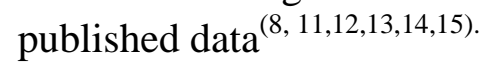

The fore mentioned considerations, besides the incongruity in the published data regarding the value of high $\mathrm{TSH}$ level on F-18 FDG PET/CT results in dedifferentiated thyroid carcinoma patients with elevated serum TG and negative I131 WBS, encouraged us to perform the current prospective study. The objectives are; firstly to assess the value of TSH level on the results of F-18 FDG PET/CT in recurrent De-DTC with elevated TG level and negative I-131 WBS and to elucidate its impact on patient management. Secondly to determine its influence on the level of serum TG cut off point that yields the best compromise between sensitivity \& specificity for F-18 FDG PET/CT results in these patients.

\section{MATERIAL \& METHODS}

This study was approved by the ethics committee of the board of nuclear medicine \& radiology at the cancer oncology center of Nasser institute hospital, Cairo, Egypt. Informed consent was obtained from all patients or their relatives with a full description of the procedures. This prospective work 
involved 38 consecutive patients with a median age of 48.5 years (range 22-75 years). All patients were investigated at the nuclear medicine unit in Nasser oncology center during the period from December 2010 till October 2012.

Patients had the following inclusion criteria: histopathologically proved differentiated thyroid carcinoma, age above 18 year old, underwent total radiosurgical thyroid ablation, rising serum TG levels above $10 \mathrm{ng} / \mathrm{ml}$ in patients with stimulated TSH level as determined by immunechemil-uminescence test during follow up and negative I-131 WBS.

Exclusion criteria includes:- positivetest for thyroglobulin auto-antibodies, pregnancy, prior treatment with retinoic acid, age below 18 year old \& the presence of second primary malignancy.

Patients fitting the inclusion \& exclusion criteria were prospectively submitted to F-18 FDG PET-CT evaluation.

At the time of initial presentation all patients underwent total thyroidectomy. Lymphadenectomy was performed in 21 patients $(55.2 \%)$ that involved central group (VI) in all of them. In addition to central lymphadenectomy unilateral \& bilateral lymphadenectomy was performed in $5(13.1 \%)$ \& 6 (15.8\%) patients respectively. Surgical treatment was followed by I-131 therapy for ablation of functional thyroid tissue \&/or treatment of residual or persistent disease.

\section{Procedures:}

\section{Iodine -131 whole body scanning:}

Primary diagnostic or post-.therapeutic I131 whole body scanning was performed
48 hours or 1 week following oral administration of radio-active I-131 using standard protocol respectively. Thyroid hormone replacement therapy was discontinued for all patients for 4 weeks, aiming at elevating serum thyroid stimulating hormone (TSH) levels above 30mIU/L.

\section{Thyroglobulin Measurement}

Blood samples for measuring serum TG levels were obtained from all patients. TG measurement was performed by immunechemil-uminescence test (ICMA; Diasorin; analytic system: Liaison analytic sensibility: 0.2 microgram/L; functional sensibility: $0.5 \mathrm{microgram} / \mathrm{L}$ ).

\section{F-18 FDG PET/CT Scanning:}

Combined PET/CT scan was performed using Siemens Biograph true V with a 64 multi-slice CT scanner. F-18 FDG$\mathrm{PET} / \mathrm{CT}$ was performed following intravenous administration of 5.5 $\mathrm{MBq} / \mathrm{Kg}$ F-18 FDG with patient fasting for 6 hours. Serum glucose levels were lower than $150 \mathrm{mg} / \mathrm{dl} \&$ images were acquired 90 minutes after tracer injection, while patient in supine position from the base of the skull to the mid-thigh region. A PET emission scan was performed over several bed positions (5to7) for 2 minutes per bed position with an axial field of view of approximately $21.6 \mathrm{~cm}$ per bed position \& in-plane spatial resolution of 2 $\mathrm{mm}$ covering the same field of view as with CT. Occasionally additional dual time localized PET-imaging was performed by obtaining delayed (after 2 hour) localized PET view for head \& neck for 2 minute using the same field of view for initial PET negative cases. 
Diagnostic CT with contrast was performed using the following parameters; $(350 \mathrm{~mA}, 120 \mathrm{KV}, 0.5$ second tube rotation time, slice thickness $5 \mathrm{~mm}, 8-\mathrm{mm}$ table feed \& $3 \mathrm{~mm}$ incremental reconstruction). Non-contrast CT was done in patients with impaired renal function (creatinine level $>2 \mathrm{mg} / \mathrm{dl}$ ) or has history of hypersensitivity for contrast media. To calculate maximal standardized uptake values (SUVmax), manually defined regions of interest (ROI) were drawn on the attenuation corrected emission image throughout the axial planes. In 20 patient $(52.6 \%)$ the F18 FDG-PET/CT procedure was performed following 4 weeks off-thyroxin therapy (stimulated group) ( $\mathrm{TSH}>30$ IU/L) while in the remaining 18 patient $(47.4 \%)$ it was performed while onthyroxin therapy (suppressed group) (TSH <0.1 IU/L).

Two expert nuclear medicine \& radiological physicians who were unaware of clinco-pathological details or other radiological data evaluated the images for local recurrence and/or distant metastases.

\section{Image analysis :}

F-18 FDG PET/CT images were assessed for presence or absence of tumor deposits by using a five-point grading system in which the lesion uptake was compared to liver uptake as follow:- 0 (no uptake): the lesion was definitely negative; 1 (lesion uptake < liver uptake): the lesion

was probably negative; 2 (lesion uptake = liver uptake): the lesion was equivocal; 3 (lesion uptake slightly higher than live): the lesion was probably positive 1;4 (intense lesion uptake that significantly higher than liver): the lesion was definitely positive.

Determination of true or false positive or negative lesions were based on visual grading score, histopathology \& FU data including clinic-radiological or F-18 FDG- PETCT as follow :

True-positive: score was 2-4 and histopathology was positive or it showed progression at follow-up sessions.

$>$ True-negative :score was $0-1$ and histology was negative or follow-up examinations did not show any pathologic result in the region of concern for at least 12-18 mo.

False-positive: score was 2-4 and histopathology was negative or it showed no progression at follow-up sessions.

False-negative: score was $0-1$ and histology was positive or follow-up examinations showed growth of the lesion(s).

\section{Determination of Regional Abnormities:-}

To compare F-18 FDG PET \& fused PET-CT results with clinic-pathological data, the body was divided into two selected areas based on lesion site as follows:-

Loco-regional area: including the neck region (enclosing the thyroid bed \& cervical nodes) and superior mediastinal region for lymph nodes.

Distant areas: including the rest of the mediastinal nodes, lungs, soft tissue \& bone lesions.

\section{Statistical Analysis:}

Sensitivity, specificity, positive \& negative predictive values as well as receiver operating characteristic (ROC) analysis were calculated using the 
Willson score which was generated by the open Epi program. The values are expressed as mean \pm standard deviation (SD) The significance of the correlations was assessed with the Fisher $\mathrm{z}$ test. In addition, the multiple comparisons were adjusted by using the Bonferroni-Holm method. $\mathrm{P}$ values of less than 0.05 were considered to indicate significant differences.

\section{RESULTS:}

Based on the level of TSH at time of PET-CT procedure the patients were subdivided into two main groups: (A) $\mathrm{TSH}$ stimulated group (i.e. TSH level > 30 $\mathrm{IU} / \mathrm{L}$, mean $=60 \pm 20 \mathrm{IU} / \mathrm{L}$ ) include 20 patients, (B) TSH suppressed group (i.e. $\mathrm{TSH}$ level $<0.1 \mathrm{IU} / \mathrm{L}$, mean $=0.007 \pm$ $0.003 \mathrm{IU} / \mathrm{L}$ ) include 18 patients.

The main clinico-pathological characteristics for stimulated \& suppressed TSH group are given in (Table 1).

On bases of histo-pathological \& follow up data for 12-18 months, a total of $79 \&$ 100 lesions were documented in TSH stimulated \& TSH suppressed groups respectively. 104 loco-regional lesions were confirmed pathologically (75 via post-operative histopathology while 29 lesions were confirmed through FNABC). The remaining 75 lesions were confirmed by monitoring their progressive course during follow up period for at least 12 months. As indicated in Table 2, a relatively higher number of loco-regional recurrent lesions (69 \& 62) compared to distant lesions ( $10 \& 38)$ were detected in the stimulated \& suppressed groups respectively $(\mathrm{P}<0.05)$. On The other hand, a significantly higher number of distant pulmonary and nodal lesions were demonstrated in suppressed compared to stimulated group $(\mathrm{P}<0.05)$. Cervical nodal lesions represent most of loco-regional recurrence in both groups with relative higher frequency in TSH stimulated (79.7\%) compared to TSH suppressed group (54\%) $(\mathrm{P}>0.05)$.

\section{F-18 FDG PET/CT:}

The results of F-18 FDG PET-CT per site in stimulated \& suppressed groups in correlation with the clinico-pathological and follow up data are illustrated in Table3. The overall results showed a significantly higher sensitivity, overall accuracy \& NPV of F-18 FDG PET-CT in stimulated $(88.6 \%, 90.5 \%$ \& 73.5$)$ compared to suppressed group (62\%, $66.5 \%$ \& 32.1) respectively $(\mathrm{P}<0.05)$. This was more obvious in detection of nodal lesions compared to thyroid bed \& pulmonary lesions. The lowest comparable sensitivities were noticed in detection of lung lesions among stimulated $(50 \%)$ and suppressed groups $(42.8 \%) \quad(\mathrm{P}>0.05)$. There were no significant difference in PPV of F-18 FDG PET-CT in both groups ( $\mathrm{P}>0.05)$.

Also the recorded mean values of SUVs in TSH stimulated F-18 FDG PET-CT group (20 patients) was significantly higher than TSH suppressed F-18 FDG PET-CT group (12 patients) in the detected loco-regional lesions $(\mathrm{P}<0.05)$. On the other hand no significant difference was detected between the mean SUV values of F-18 FDG PET-CT in TSH stimulated (5) \& suppressed group (3) in distant lesions $(\mathrm{P}>0.05)$.

\section{Serum thyroglobulin results:}

TG level was assessed during high TSH level (>30 IU/L) in both groups of recurrent De-DTC patients. There was a 
statistically significant variation in the mean value of TG level between TSH stimulated group $(48 \pm 36 \mathrm{ng} / \mathrm{ml})$ and TSH suppressed group (mean $85 \pm 70$ $\mathrm{ng} / \mathrm{ml})(\mathrm{P}<0.05)$.

Receiver operating characteristic (ROC) revealed a lower TG cut off point for TSH stimulated F-18 FDG PET-CT (15 $\mathrm{ng} / \mathrm{ml}$ ) compared to TSH suppressed F18 FDG PET-CT group (21 ng/ml) that provide the best compromised between sensitivity \& specificity in respect to cost efficiency benefit (Figure1). The sensitivity \& specificity are significantly improved with values higher than $15 \&$ $21 \mathrm{ng} / \mathrm{ml}$ in F-18 FDG PET-CT TSH stimulated and suppressed group respectively due to reduced false negative lesions vice versa (Table 4) $(\mathrm{P}<0.05)$.

\section{Change in restaging in recurrent De-DTC patients: -}

In comparison to $\mathrm{CT}$, the added value of F-18 FDG PET/CT in respect to restaging of recurrent De-DTC patients was significantly higher in TSH stimulated (40\%) compared to TSH suppressed (11.2\%) group $(\mathrm{P}<0.05)$ (Table 5). In TSH stimulated group a more numerable number of nodal lesions were detected compared to CT. Therefore Up-staging was noticed in 6 patients (2 patients changes from N0 to N1a (Figure 2), 2 from N0 to N1b \& 2 patients from N1a to N1b) while down staging occurs in two patient from N1b to N1a. In TSH

suppressed group, down staging was noticed in two patients from N1b to N0.
The added value of $\mathrm{CT}$ compared to PET/CT was significantly lower in TSH stimulated $5 \%$ compared to $\mathrm{TSH}$ suppressed group (16.6\%) in the form of over-staging. This influence was noticed in detection of more number of pulmonary (Figure 3) rather than nodal lesions (Figure4).

\section{DISCUSSION}

The appropriate diagnostic consensus that assures the best yield in terms of high diagnostic accuracy and cost effectiveness of F-18-FDG PET/CT in respect to serum TG level in detection of recurrence in DeDTC patients with rising TG level and negative I-131 WBS is not achieved yet. Moreover the impact of high TSH level on effectiveness of FDG PET/CT in such diagnostic consensus is not completely certain and lack of agreement is reflected in published data ${ }^{(8,13,14,15)}$. It was possible in the present study to assess the effects of TSH level on the results of F-18-FDG PET-CT in recurrent de-differentiated thyroid carcinoma patients with elevated TG level and negative I-131 WBS and to elucidate its impact on patient management. Moreover to determine a correlation between variations in TSH level and the values of serum TG cut off point in these patients.

TSH in differentiated cancer thyroid stimulates metabolism, glucose transport \& glycolysis of malignant thyroid cells. Moreover it works as a growth factor for malignant thyroid cells through stimulation of tumour growth, invasion and angiogenesis. 
Table (1): Clinico-pathological characteristics of TSH stimulated \& TSH suppressed groups in recurrent De-DTC patients $(n=38)$

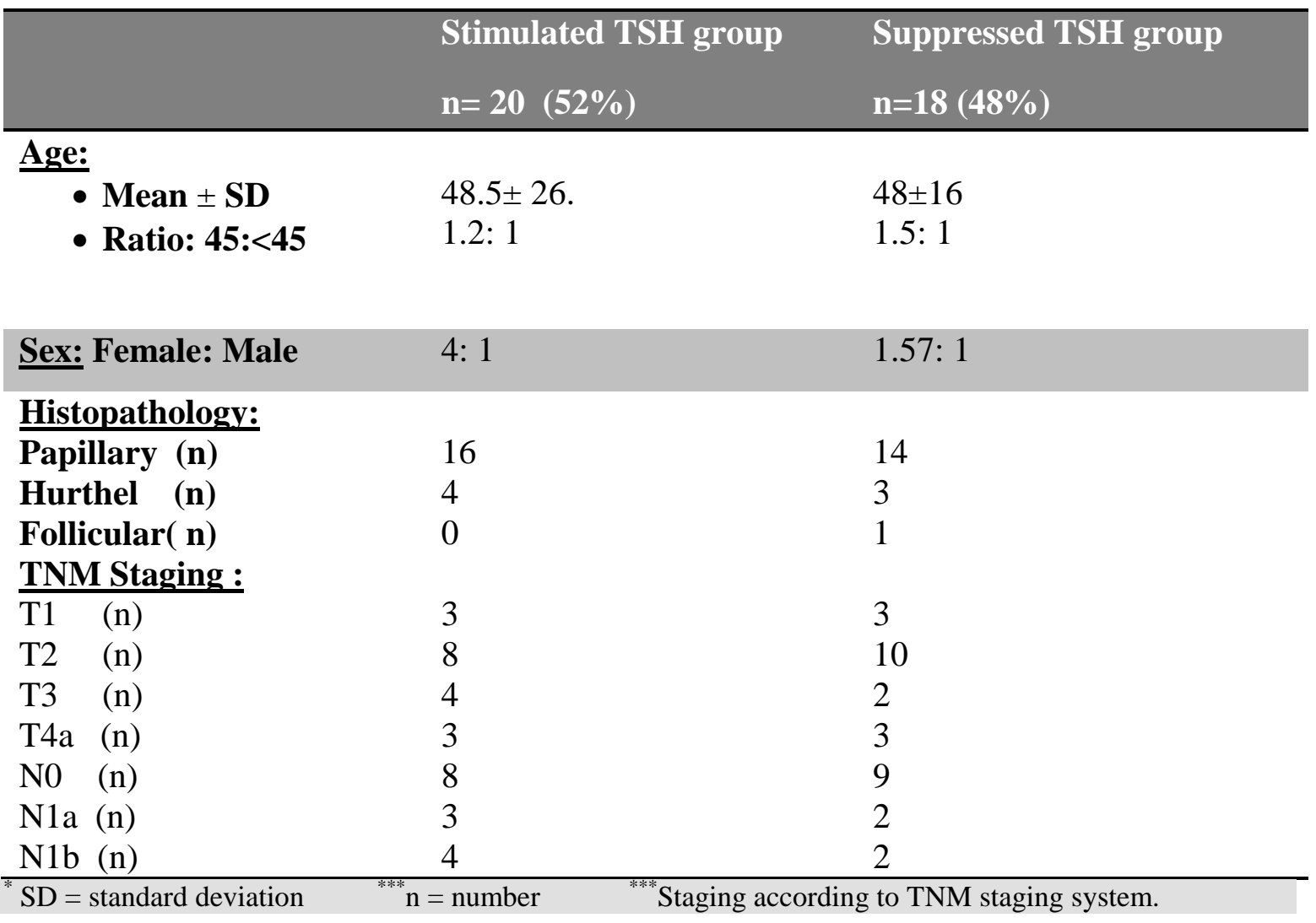

Table 2:- Overall Results of clinico-pathological \& follow up data in respect to site in TSH stimulated \& suppressed groups in recurrent de-DTC Patients $(n=38)$ :

\begin{tabular}{|c|c|c|c|c|c|}
\hline \multirow{2}{*}{ Site of recurrence } & \multicolumn{2}{|c|}{ Stimulated TSH group } & \multicolumn{2}{|c|}{ Suppressed TSH group } & \multirow{2}{*}{$\begin{array}{c}\text { P- } \\
\text { value } \\
\end{array}$} \\
\hline & $\mathrm{N} / \mathrm{T}$ & Freq $(\%)$ & $\mathrm{N}$ & Freq $(\%)$ & \\
\hline$\underline{\text { Loco-regional }}$ & $69 / 79$ & $87.3 \%$ & $62 / 100$ & $62 \%$ & $<0.05$ \\
\hline $\begin{array}{l}\text { - } \frac{\text { Thyroid bed }}{\text { Nodes: }} \\
\text { cervical } \\
\text { Sup. Med }\end{array}$ & $\begin{array}{c}3 / 79 \\
66 / 79 \\
63 / 79 \\
3 / 79\end{array}$ & $\begin{array}{c}3.8 \% \\
83.5 \% \\
79.7 \% \\
3.8 \%\end{array}$ & $\begin{array}{c}3 / 100 \\
59 / 100 \\
54 / 100 \\
5 / 100\end{array}$ & $\begin{array}{c}3 \% \\
59 \% \\
54 \% \\
5 \%\end{array}$ & \\
\hline $\begin{array}{r}\text { Distant } \\
\qquad \quad \text { Nodes } \\
-\quad \text { Lungs }\end{array}$ & $\begin{array}{c}10 / 79 \\
6 / 79 \\
4 / 79\end{array}$ & $\begin{array}{c}12.6 \% \\
7.6 \% \\
5 \%\end{array}$ & $\begin{array}{l}38 / 100 \\
17 / 100 \\
21 / 100\end{array}$ & $\begin{array}{l}38 \% \\
17 \% \\
21 \%\end{array}$ & $<0.05$ \\
\hline Overall (n) (\%) & 79 & $100 \%$ & 100 & $100 \%$ & $\begin{array}{l}\mathrm{P}<0.0 \\
5\end{array}$ \\
\hline
\end{tabular}

$* \mathrm{~N} ;$ number $* * \mathrm{~T}$ : total number ***Freq ; frequency**** Sup. Med : superior mediastinum. 
Table 3 : Results of F-18 FDG PET-CT per site in TSH stimulated \& suppressed groups in comparison to clinico-pathological and FU data in 38 recurrent DeDTC Patients :

\begin{tabular}{|c|c|c|c|c|c|}
\hline \multirow[t]{2}{*}{ Site } & \multicolumn{2}{|c|}{$\begin{array}{c}\text { TSH Stimulated group F-18 FDG- } \\
\text { PET CT }\end{array}$} & \multicolumn{2}{|c|}{$\begin{array}{l}\text { TSH Suppressed group F-18 } \\
\text { FDG PET-CT }\end{array}$} & \multirow[b]{2}{*}{ P-value } \\
\hline & N/Tn & Sensitivity & N/Tn & Sensitivity & \\
\hline $\begin{array}{l}\text { Loco- } \\
\text { regional } \\
\text { Thyroid } \\
\text { bed: } \\
\text { Nodes: } \\
\text {.Cervical } \\
\text {.Sup Med }\end{array}$ & $\begin{array}{c}62 / 69 \\
3 / 3 \\
59 / 66 \\
56 / 63 \\
3 / 3\end{array}$ & $\begin{array}{c}89.8 \% \\
100 \% \\
89.3 \% \\
88.8 \% \\
100 \%\end{array}$ & $\begin{array}{c}41 / 62 \\
3 / 3 \\
38 / 59 \\
33 / 54 \\
5 / 5\end{array}$ & $\begin{array}{c}66 \% \\
100 \% \\
64.5 \% \\
61 \% \\
100 \%\end{array}$ & $<0.05$ \\
\hline $\begin{array}{l}\text { Distant } \\
\text { Nodes n } \\
\text { Lungs:n }\end{array}$ & $\begin{array}{l}8 / 10 \\
6 / 6 \\
2 / 4\end{array}$ & $\begin{array}{c}80 \% \\
100 \% \\
50 \%\end{array}$ & $\begin{array}{c}21 / 38 \\
12 / 17 \\
9 / 21\end{array}$ & $\begin{array}{l}55.2 \% \\
70.5 \% \\
42.8 \%\end{array}$ & $\begin{array}{l}<0.05 \\
>0.05\end{array}$ \\
\hline Overall & $70 / 79$ & 88.6 & $62 / 100$ & $62 \%$ & $<0.05$ \\
\hline $\begin{array}{l}\text { Accuracy } \\
\text { NPV } \\
\text { PPV }\end{array}$ & $\begin{array}{r}95 \\
25 \\
70\end{array}$ & $\begin{array}{c}90.5 \% \\
73.5 \% \\
98.5 \%\end{array}$ & $\begin{array}{l}80 / \\
18 / \\
62 /\end{array}$ & $\begin{array}{l}66.6 \% \\
32.1 \% \\
96.8 \%\end{array}$ & $\begin{array}{l}<0.05 \\
<0.05 \\
>0.05\end{array}$ \\
\hline
\end{tabular}

$* \mathrm{n}=$ number $* * \mathrm{Tn}=$ total number $* * *$ Sup. Med $=$ superior mediastinum $* * * * \mathrm{NPV}=$ negative predictive value $* * * * * \mathrm{PPV}=$ Positive predictive value. 
Table 4: Results of F-18 FDG PET-CT in correlation to serum TG level in TSH stimulated \&suppressed groups in DTC Patients $(n=38)$ :

\begin{tabular}{|l|l|l|l|l|l|}
\hline \multirow{2}{*}{} & \multicolumn{2}{|c|}{ TSH Stimulated group } & \multicolumn{2}{c|}{ TSH Suppressed group } & P-value \\
\cline { 2 - 5 } & $\begin{array}{l}\text { TG cut-off } \\
<15 \mathrm{ng} / \mathrm{ml}\end{array}$ & $\begin{array}{l}\text { TG cut-off } \\
\geq 15 \mathrm{ng} / \mathrm{ml}\end{array}$ & $\begin{array}{l}\text { TG cut-off } \\
<21 \mathrm{ng} / \mathrm{ml}\end{array}$ & $\begin{array}{l}\text { TG cut-off } \geq \\
21 \mathrm{ng} / \mathrm{ml}\end{array}$ & \\
\hline - TP lesions & 25 & 45 & 22 & 40 & $\mathrm{P}<0.05$ \\
- FN lesions & 7 & 2 & 20 & 18 & \\
- Sensitivity & 78 & $95.7 \%$ & $52.3 \%$ & $68.9 \%$ & \\
- Specificity & 90 & $100 \%$ & $90 \%$ & $100 \%$ & \\
\hline
\end{tabular}

$* \mathrm{TG}$; thyroglobulin $* * \mathrm{TP}=$ true positive $* * \mathrm{FN}=$ False negative

Table 5 : Comparison between CT \& F-18 FDG PET-CT in respect to change in restaging in TSH Stimulated \& TSH suppressed group of recurrent De-DTC patients(n=38):

\begin{tabular}{|l|c|c|c|c|c|}
\hline & \multicolumn{2}{|c|}{ TSH Stimulated group } & \multicolumn{2}{c|}{ TSH Suppressed group } & $\begin{array}{c}\text { P- } \\
\text { value }\end{array}$ \\
\hline & CT & F-18 FDG PET/CT & CT & F-18 FDG PET/CT & \\
\hline Over-staging & 1 & 6 & 3 & 0 & \multirow{2}{*}{0.05} \\
\cline { 1 - 5 } Down- staging & 0 & 2 & 0 & 2 & \\
\cline { 1 - 5 } No changes & 11 & 11 & 13 & 13 & \\
\hline
\end{tabular}




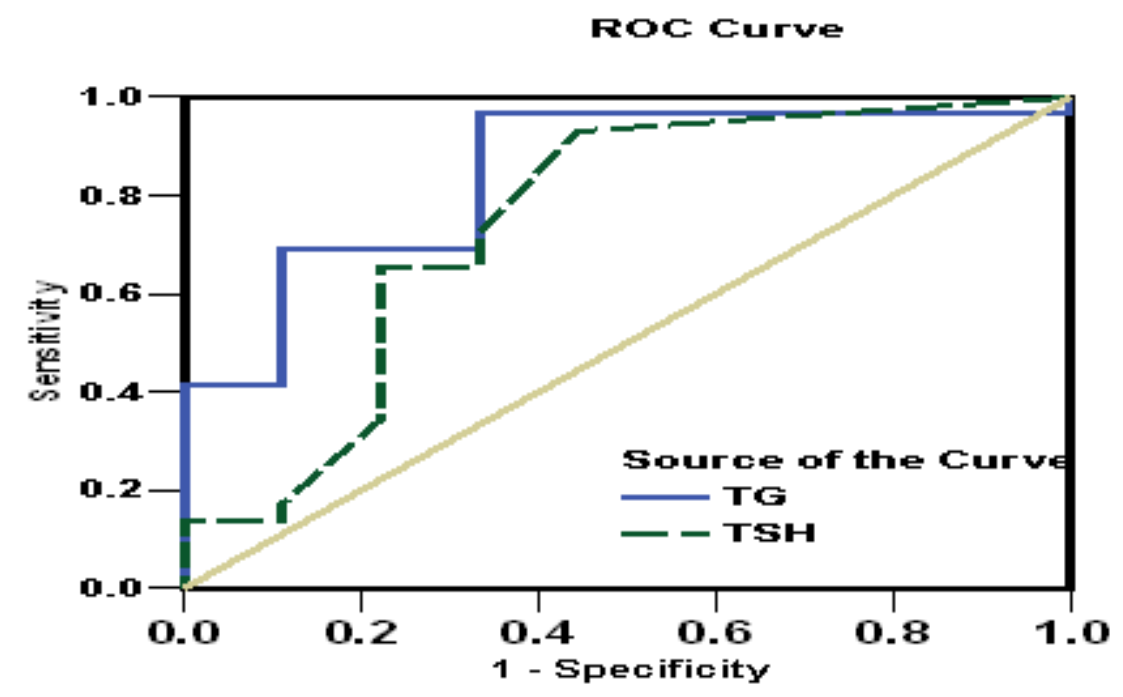

Figure 1 : ROC curve analysis marks a value of $15 \& 21 \mathrm{ng} / \mathrm{ml}$ as a cut off points for serum TG level in TSH stimulated and suppressed group in recurrent De-DTC patient respectively $(n=38)$.
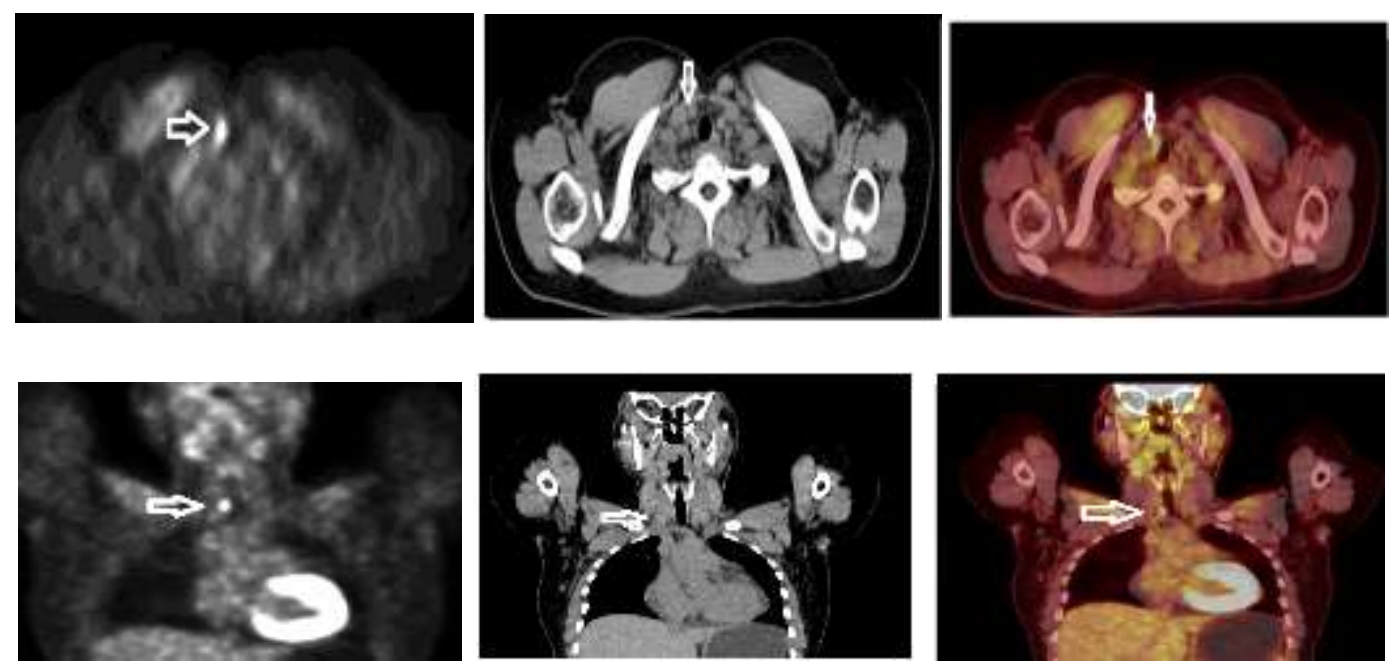

Figure 2: 31 year old female patient had elevated serum TG level $(19 \mathrm{ng} / \mathrm{ml})$ \& negative I-31 WBS 2.5 year post- total radio-surgical total thyroid ablation for papillary thyroid carcinoma (T2 N0M0). Axial (upper row) \& coronal (lower row) sections for TSH stimulated F-18 FDG PET, CT \& fused PET/CT sections arranged from left to right respectively show : sub-centimetric FDG avid Rt. Paratracheal nodal lesion at level VI (arrows) detected by PET \& was active in fused PET/CT with max SUV $=28$ but missed in CT. This nodal lesion was confirmed to be metastatic papillary carcinoma histopathologically. Therefore TSH stimulated F-18 FDG PET/CT over-stage this patient from N0 to N1a compared to CT. 

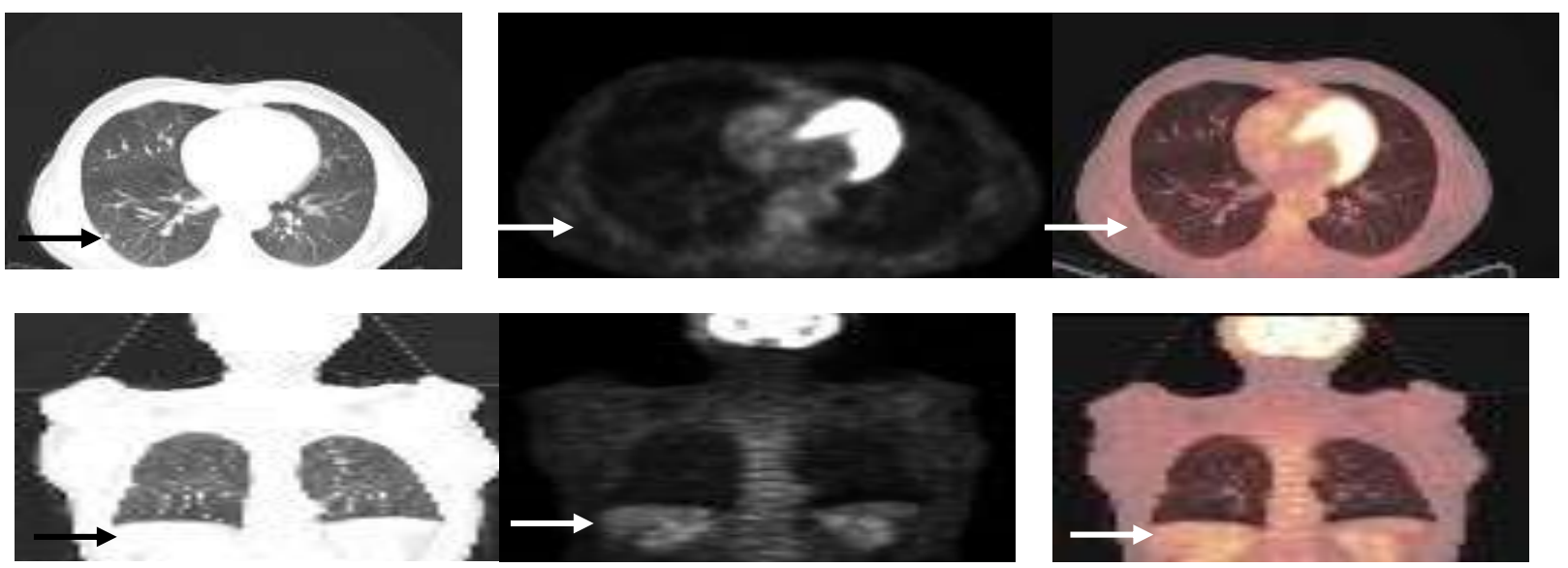

Figure 3:- 41 year old male patient had elevated serum TG level $(200 \mathrm{ng} / \mathrm{ml})$ \& negative I-31 WBS 2 year post- total radio-surgical thyroid ablation for papillary thyroid carcinoma (T3 NOM0). Axial (upper row) \& coronal (lower row) sections for TSH stimulated CT, F-18 FDG PET \& fused PET/CT sections arranged from left to right respectively show : CT depicted $1 \mathrm{~cm}$ pulmonary nodule in apical segment of Rt. Lower lung lobe (arrowed) that missed in F-18 FDG PET \& was inactive in fused PET/CT image. Multiple metabolically inactive CT depicted nodules were also seen that progressed during follow up. Therefore CT over-stage this patient from M0 to M1 compared to TSH suppressed F-18 FDG PET/CT.
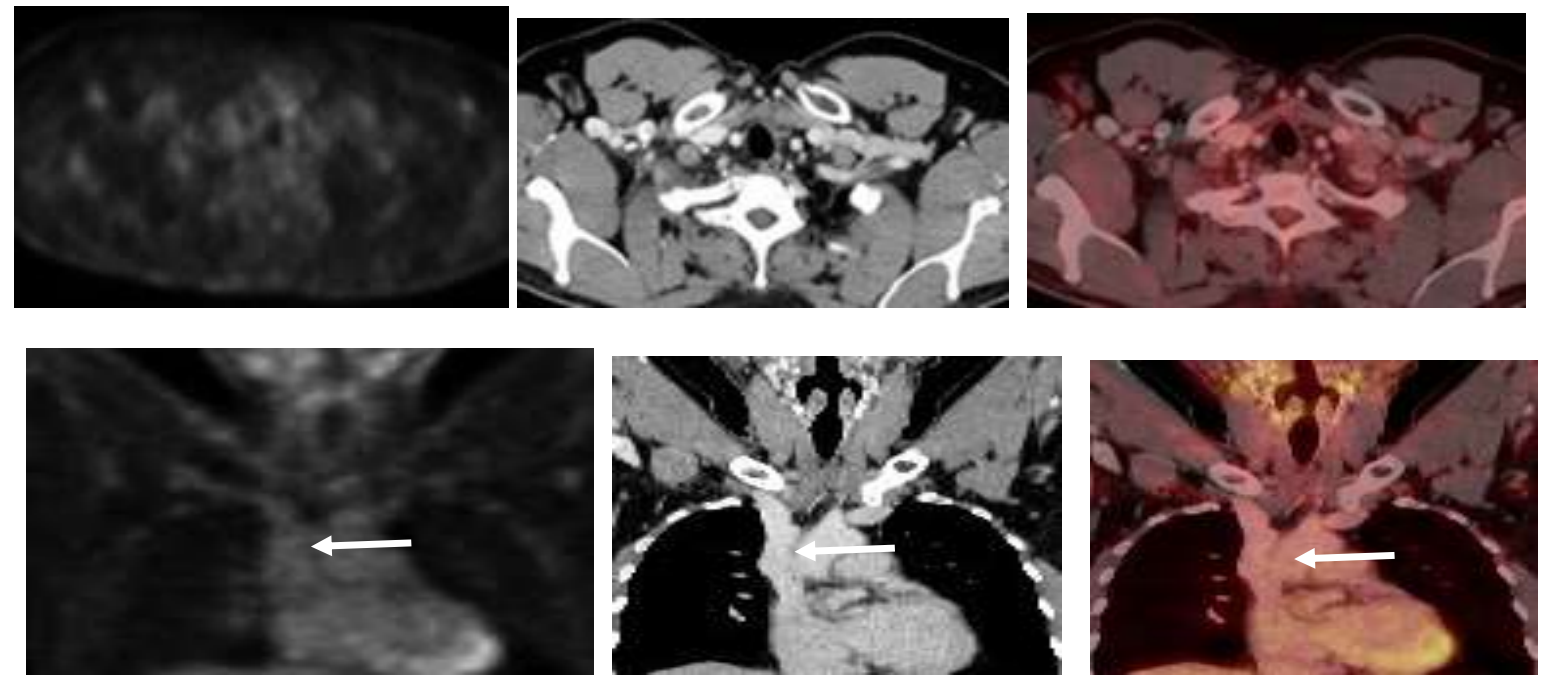

Figure 4: 41 year old male patient had elevated serum TG level $(18 \mathrm{ng} / \mathrm{ml})$ \& negative I31 WBS 3 year post- total radio-surgical thyroid ablation and central neck nodal lymphadenectomy (L VI) for papillary thyroid carcinoma (T2,N1a,M0). Axial (upper row) \& coronal (lower row) sections for TSH suppressed F-18 FDG PET, CT \& fused PET/CT images arranged from left to right respectively show: $1 \mathrm{~cm}$ sized non-FDG avid nodal lesion at level VI (arrowed) detected by CT but missed in F-18 FDG PET \& was inactive in fused PET/CT slices. This nodal lesion was confirmed to be metastatic papillary carcinoma histopathologically. Therefore CT over stage this patient from N0 to N1a compared to TSH suppressed F-18 FDG PET/CT. 
Its role in stimulation of I-131 uptake \& retention in DTC patient is well established ${ }^{(8,14,16,17,18,19)}$. In Contrary there are wide variations in the reported data regarding its role in stimulation of FDG uptake in recurrent De-DTC patients with elevated TG and negative I-131 WBS. Based on several experimental and clinical data some authors support TSH dependency of FDG uptake by De-DTC recurrence and others not. Those who support TSH role in increasing FDG uptake by De-DTC lesions rely on its impact in enhancing metabolic activity \& over-expression of GIUT-1 receptors and glucose consumption. In contrast other authors deny TSH dependency and alternatively highlight autonomic nature for recurrent De-DTC lesions ${ }^{8,14,15,20,21)}$.

In agreement with other published data $(14,15,22,23,24)$, a significantly higher accuracy, overall sensitivity \& NPV $(90.5 \%, 88.6 \%$ \& $73.5 \%$ respectively) were noted in TSH stimulated compared to TSH suppressed groups ( $66.6 \%, 62 \% \&$ $32.1 \%$ respectively $)(\mathrm{P}<0.05)$. The differences in sensitivities were more obvious in nodal rather than pulmonary lesions. The relative unsatisfactory low NPVs for TSH stimulated (73.5\%) and TSH suppressed group (32.1\%) is related to the low yield in detection of small pulmonary lesions in both groups. Finally a high specificity and PPV results were demonstrated due to limited number of false positive lesions in both groups $(\mathrm{P}>0.05)$. Beside to the additive value of $\mathrm{TSH}$, interaction of site, size, metabolic activity, heterogeneity of differentiation or respiratory motion may play a role in such findings. Moreover possibility of a relatively higher TSH metabolic dependency in nodal compared to pulmonary lesions that may alternatively hold autonomic nature should be considered. This suggestion is supported by the noticed significant differences in the recorded mean values of SUVs in both groups that were significantly higher in TSH stimulated group compared to TSH suppressed group in loco-regional rather than pulmonary lesions.

The diagnostic value of TG level in follow up of DTC is well established in the literature ${ }^{(25,26,27)}$. In the current study the mean serum TG values were significantly higher in TSH suppressed group compared to TSH stimulated group $(\mathrm{P}<0.05)$. The more frequent pulmonary metastases in suppressed compared to stimulated groups contribute to such finding ${ }^{(25,27)}$.

The diagnostic use of F-18 FDG PET/CT is dependent on the serum TG level in dedifferentiated thyroid cancer patients with negative I-131 WBS ${ }^{(8,22,28)}$.

For a complete consensus to define the optimal diagnostic utility of F-18-FDG $\mathrm{PET} / \mathrm{CT}$ in de-differentiated thyroid cancer the level of serum TG cut off point that provides the utmost sensitivity \& specificity for its use is clinically desired. Receiver operating characteristic curve analysis was used to mark a TG cut off value that point a certain accuracy value to the imaging method and in order to determine the optimal cost effectiveness for the use of F-18-FDG PET/CT in dedifferentiated thyroid cancer. ROC curve analysis mark a significantly lower level of TG cut off point for TSH stimulated group (15 $\mathrm{ng} / \mathrm{ml})$ compared to suppressed group $(21 \mathrm{ng} / \mathrm{ml})(\mathrm{P}<0.05)$. 
Change in Restaging of recurrent DeDTC patients :-

In comparison to $\mathrm{CT}$, The impact of F-18 FDG PET/CT on restaging of recurrent De-DTC patients was significantly higher in TSH stimulated group (40\%) compared to $\mathrm{TSH}$ suppressed group $(11.2 \%)$ with enhanced sensitivity and specificity in determination of nodal lesions.

In contrast a significantly higher influence of CT was demonstrated in TSH suppressed $16.6 \%$ compared to TSH stimulated group 5\% due to enhanced sensitivity in determination of pulmonary lesions.

The strength of the study lies in inclusion of fairly comparable groups of patients with no significant difference in age, sex, staging as well as pathological sub-types. It shows the impact of TSH level on the overall results and lesion site related accuracy of F-18 FDG PET/CT in dedifferentiated thyroid carcinoma. Also it explore the influence of variations of TSH level on the determination of value of TG cut off point that permits utmost sensitivity \& specificity of F-18 FDG PET/CT results. Finally the study determines the possible impact of variations of TSH level on the value of F-

\section{CONCLUSIONS:}

High TSH seems to have site dependant enhanced F-18 FDG PET/CT efficiency in recurrent de-differentiated thyroid carcinoma patients with negative I-131 WBS and elevated TG level that is more
18 FDG PET/CT in respect to change in patient management.

The limitations of this prospective study include the inability to correlate F-18 FDG PET-CT results with specific molecular \& immune-histochemical markers for de-differentiation that determine either the predisposing gene mutation (e.g BRAF-V600E) or subcellular molecular changes which are not applied routinely in our institute.

Secondly, the accuracy of F-18 FDG PET/CT was partially but not fully established on basis of histo-pathological examination on supposed secondary lesions. Alternatively a limited follow up of TG value as well as CT results were used. However this is difficult to eliminate because of ethical \& clinical concern in practice.

Thirdly this study was carried out on a relatively small number of patients with variation in duration of disease and on short-term basis.

Finally the study did not consider the possible influence in variations of TSH levels in respect to the accuracy of F-18 FDG PET-CT in TSH stimulated group.

obvious in nodal rather than pulmonary lesions. Being more sensitive, TSH stimulated F-18 FDG PET/CT, marks a lower TG cut off point compared to TSH suppressed F-18 FDG PET/CT 


\section{REFRENCES:}

1. Parkin DM, Pisani P, Ferlay J.: Golobal cancer statistics; CA cancer J Clin 1999; 49 (1):33-64.

2. Schlumberger MJ,: Papillary and follicular thyroid carcinoma; N Engl J Med 1998; 338:297-306.

3. Cheung CC, Ezzat S, Freeman JL, Rosen IB, Asa SL, "Immunohistochemical diagnosis of papillary thyroid carcinoma," Mod Pathol 2001, 14 (4), 338-342.

4. Braga-Basaria M, Ringel MD,: "Clinical review 158: beyond radioiodine: A review of potential new therapeutic approaches for thyroid cancer," J Clin Endocrinol Metab 2003, 88 (5) 1947-1960.

5. Sarlis NJ, Benvenga S: Molecular signalling in thyroid cancer In: Farid NR ed. Molecular bases of thyroid. Boston Kluwer 2004; 235-263.

6. Cooper DS, Dohorty GM, Haugen BR, Kloos RT, Lee SL, Manel SJ, Mazzaferri EL et al.: Revised American Thyroid association management guideline for patients with thyroid nodules and differentiated cancer thyroid. Thyroid 2009; 19 (11):1167-214.

7. Antonelli A, Ferri C, Ferrari MS, Sebastiani M, colaci M, Ruffilli I et al.: New Targeted Molecular Therapies for De-differentiated Thyroid Cancer; J Oncol 2010; 2010:921682.

8. Bertagna $\mathbf{F}$, Biasiotto $\mathbf{G}$, Orlando E, Basio G, Giubbini R: Role of ${ }^{18}$ F-Fluro-deoxyglucose positron emission tomography/computed tomography in patients affected by differentiated thyroid carcinoma, high thyroglobulin level, and negative I131 scan: review of the literature. Jpn J Radiol 2010; 28:629-36.
9. Romei C, Ciampi R, Faviana $\mathbf{P}$, Agate L, Molinaro E, Bottici $V$ et al.: "BRAF V600E mutation, but not RET/PTC rearrangements, is correlated with a lower expression of both thyroperoxidase and sodium iodide symporter genes in papillary thyroid cancer," Endocr Relat Cancer 2008 ; 15( 2): 511-520.

10. Oler G, Cerutti JM: "High prevalence of BRAF mutation in a Brazilian cohort of patients with sporadic papillary thyroid carcinomas: correlation with more aggressive phenotype and decreased expression of iodide-metabolizing genes," Cancer 2009; 115 (5) 972980.

11. Bunone G, Vigneri $\mathbf{P}$, Mariani L, Butó S, Collini P, Pilotti $S$ et al.: "Expression of angiogenesis stimulators and inhibitors in human thyroid tumors and correlation with clinical pathological features," Am J Pathol 1999; 155(6):1967-76.

12. De la Torre NG, Buley I, Wass JA, Turner HE, "Angiogenesis and lymphangiogenesis in thyroid proliferative lesions: relationship to type and tumour behavior," Endocr Relat Cancer 2006; 13(3): 931-944.

13. Mittendorf EA, Wang $\mathbf{X}$, Perrier ND, Francis AM, Edeiken BS, Shapiro SE et al. Follow up of patients with papillary thyroid carcinoma; in search of the optimal algorithm. J Am Coll Surg 2007; 205(2); 239-47.

14. Aygun N. Imaging of recurrent thyroid carcinoma ; Otolaryngol Clin North Am. 2008; 41(6):1095-106.

15. Kim SJ, Lee TH, Kim IJ, Kim YK. Clinical implication of F-18 FDG PET-CT for differentiated thyroid cancer in patients with negative diagnostic iodine-123scan and 
elevated thyroglobulin. Eur. J Radiol. 2009; (70):17-24.

16. Filetti S, Damante G, Foti D, Thyrotropin stimulates glucose transport in cultured rat thyroid cells. Endocrinology 1987; 120(6):2576-81.

17. Diechen JT, Schmidt C, Prante O, Maschauer S, Papdopulos T, Kuwert T, Influence of TSH on uptake of F-18- fluoro-deaoxyglucose in human thyroid cells in vitro. Eur $\mathbf{J}$ Nucl Med Mol Imaging 2004; 31(4):507-12.

18. Blaser D, Machauer S, Kuwert T, Prante O:. In vitro studies on signal transduction of thyroidal uptake of ${ }^{18}$ FDG and ${ }^{131}$ I-iodide. J Nucl Med 2006; 47:1382-8.

19. Mazzaferri EL, Kloos RT. Is diagnostic iodine I-131 scanning with recombinant human TSH useful in the follow up of differentiated thyroid cancer after thyroid ablation? J Clin Endocrinol Metab 2002; 87 (4):14908.

20. Wang W, Macapinlac $\mathbf{H}$, Larson SM, Yeh SD, Akhrust T, Finn RD et al. 18-F-2-deoxy-D-glucose positron emission tomography localize residual thyroid cancer in patients with negative I-131 whole body scans and elevated serum thyroglobulin levels. J Clin Endocrinol Metab. 1999; 84(7): 2291302.

21. Ruiz Franco-Baux JV, Borrego Dorado I, Gomez Camarero P, Rodriquez JR, Vazquez Albertino RJ, Navarro Gonzalez $E$ et al.: F18- Fluro-deoxyglucose positron emission tomography in patient with differentiated thyroid cancer who present with elevated thyroglobulin level and negative I-131 whole body scanning. Rev Esp Med Nucl. 2005; 24 (1):5-13.
22. Frilling A, Tecklenborg $\mathbf{K}$, Gorges R, Weber F, Clausen M, Broelsch EC:. Preoperative diagnostic value of ((18)F) fluro-deoxyglucose positron emission tomography in patients with radio-iodine- negative recurrent well differentiated thyroid carcinoma. Ann Surg 2001; 234 (6):804-11.

23. Robbins RJ, Wan Q, Grewal RK, Reibke R, Gonen M, Strauss HW, et al:. Real-time prognosis for metastatic thyroid carcinoma based on $\quad 2-\left\{{ }^{18} \mathrm{~F}\right\} \quad$ fluro-deoxyglucose positron emission tomography scanning. J Clin Endocrinol Metab 2006; 91(2):498-505.

24. Stokkel MPM, Duchateau CS, Dragoiescu C.: The value of FDGPET in follow up of differentiatewd thyroid cancer ; a review of the literature, QJ Nucl Med Mol Imaging 2006; 50(1):78-87.

25. Lubin E, Mechlis-Frish S, Zatz S, Shimoni A, Segal K, Avraham A et al., Serum thyroglobulin and I-131 whole body scan in diagnosis and assessment of treatment for metastatic differentiated thyroid carcinoma. J Nucl Med 1994; 35(2):257-62.

26. Kloos RT, Mazzaferri EL: A single recombinant human thyrotropinstimulated serum thyroglobulin measurement predicts differentiated thyroid carcinoma metastases three to five years later. J Clin Endocrinol Metab 2005; 90 (9):5047-57.

27. Mazzaferri EL. Will highly sensitive thyroglobulin assays change the management of thyroid cancer? Clin Endocrinol (oxf) 2007;67(3):321-3.

28. Lind P, Kresnik E, Kumnig G, Gallowitsch HJ, Igerc I, Matschnig S et al. 18-F-FDG-PET in follow up of thyroid cancer, Acta Med Austriaca, 2003;30 (1):17-21. 